\title{
Iranian English Foreign Language Learners' Learning Style Sensory Preferences and Their Speaking Strategy Use Across Proficiency
}

\author{
Tania Samadian \\ Islamic Azad University, Science and Research Branch,
}

Tehran, Iran

\author{
Parviz Birjandi \\ Allameh Tabatabai University, \\ Tehran, Iran
}

\begin{abstract}
This study investigates the relationship between Iranian EFL (English as a Foreign Language) learners' sensory preferences: Visual, Audial, and Haptic (VAH) and the learners' speaking strategy use across proficiency. To this end 146 Iranian EFL learners studying English at different levels of language proficiency, participated in this study. O’Brien's (1990) learning channel preference checklist was given to students to determine their sensory preferences. In addition, a Speaking Strategy questionnaire (an adaptation of strategy inventory for language learning (SILL), focusing on strategies used at the time of Speaking) was also given to the students in another session. The data were analyzed using multivariate ANOVA (MANOVA) in order to probe the relationship between Iranian EFL Learners' Learning Style Sensory Preferences and their speaking strategy use across proficiency. Based on the results, it can be claimed that there was a weak to moderate interaction between the proficiency levels and preference of speaking strategies on the learning styles of the Iranian EFL learners.
\end{abstract}

Keywords: sensory preferences, learning style, oral proficiency, speaking strategy

\section{Introduction}

Today in the field of second language learning, it is unanimously agreed by most scholars and practitioners that both the degree and rate of achievement in the process of foreign language learning are affected by individual learner differences, e.g., learning styles (Ellis, 1985; Williams \& Burden, 1997). Along the same line, without a doubt language learning strategies influence second language learning. Hence, the research on the strategies learners use, how and when, aids teachers and researchers alike. In addition, a broad variety of factors may affect the choice of language learning strategies, i.e., age, prior knowledge, attitude, motivation, aptitude, and anxiety in second language learning have been shown to be strongly related to the choice of language learning strategies (Guilloteax \& Dornyei, 2008; Ortega, 2003; Vandergrift, 2005). The present study will focus on the relationship between Iranian EFL learners' learning sensory preferences (VAH) and the learners' speaking strategy use across proficiency.

Language learning strategies, as one of the significant criteria in language learning amongst many, have

Tania Samadian, Ph.D. candidate, Department of Foreign Languages and Literature, Science and Research Branch, Islamic Azad University.

Parviz Birjandi, Ph.D., Faculty of Foreign Languages and Literature, Allameh Tabatabai University. 
received a growing amount of interest and numerous research studies have been conducted (Nakatani, 2006; Razmjoo \& Ghasemi, 2011; Wu, 2008; Yang, 2007; Yaman \& Kavasoglu, 2013) to name but a few. Learning style research has not lagged behind and quite a number of research studies have been done in Iran in recent years. (Behabadi \& Behfrouz, 2013; Moghadam, Razavi, \& Jayervand, 2013; Nosratinia, Mojri, \& Sarabchian, 2014; Ramezani, Dehgahi, \& Hashemi, 2015; Vaezi \& Shahroosvand, 2015). However, no research has been conducted with reference to learning style and specifically speaking strategy across proficiency.

\section{Review of Literature}

\section{Learning Strategies}

According to Chamot (2004), learning strategies are:

The conscious thoughts and actions that learners take in order to achieve a learning goal. Strategic learners have a good understanding of what a task entails, and the ability to orchestrate the strategies that best meet both the task demands and their own learning strengths. (p. 14)

Various researchers (Dornyei, 2005; Oxford, 1990; Rubin, 1987; Stern, 1992) have classified language learning strategies based on their unique viewpoint on this notion. Among all the taxonomies, probably Oxford's (1990) is the most accepted; in which she divided Language Learning Strategies (LLS) into two main categories, each containing sub-categories:

(1) Direct strategies: memory, cognitive, compensation strategies, communication strategies;

(2) Indirect strategies: metacognitive strategies, affective strategies, social strategies.

Numerous studies have been conducted in the LLS. However, few have done research on speaking language learning strategies (Nakatani, 2006; Razmjoo \& Ghasemi, 2011; Yaman \& Kavasoglu, 2013).

Nakatani (2006) developed a questionnaire, named the Oral Communication Strategy Inventory (OCSI). This study uncovered that students with high oral proficiency tended to use specific strategies, such as social affective strategies, fluency-oriented strategies, and negotiation of meaning. Razmjoo and Ghasemi (2011) developed a model describing speaking strategies for EFL learners by taking into account the effects of learners' gender and proficiency on the application of strategies. Along the lines of Nakatani's study, Yaman and Kavasoglu (2013) carried out a study in which they adapted OCSI into Turkish. It was concluded that non-verbal strategies which existed in Nakatani's original inventory did not appear in the adaptation form. Instead, the items that consisted of nonverbal strategies gave loadings to negotiation for meaning strategies, which implied that the purpose of the interlocutors while using one strategy may be culture specific.

\section{Learning Style}

According to Reid (1987), learning styles or learning preferences are the various ways of how a learner acquires, retains, and retrieves information. Reid (1995) believes that one major category of learning styles relevant to the field of foreign language learning is sensory or perceptual learning styles which are related to the physical environment in which we learn and involve using our senses in order to perceive data. Reid (1995) classifies learning styles into auditory (preference of learning through listening), visual (preference of learning through seeing), tactile (preference of hands-on work), kinesthetic (preference of whole-body movement), individual and group learning. O'Brien (1990), however, looks at three sensory learning style preferences: visual, auditory, and haptic learning.

Many style related research studies have been conducted in TEFL (Teaching English as a Foreign 
Language) and most recently a number of Iranian researchers have become just as interested as their international counterparts (Behabadi \& Behfrouz, 2013; Fahim \& Samadian, 2011; Moghadam, Razavi, \& Jayervand, 2013; Nosratinia, Mojri, \& Sarabchian, 2014; Ramezani, Dehgahi, \& Hashemi, 2015; Vaezi \& Shahroosvand, 2015).

Behabadi and Behfrouz (2013) attempted to explore the characteristics of good language learners in the Iranian context. In terms of styles, the findings discovered that there was a high correlation between high scores in IELTS and possessing Kinesthetic, Auditory, and Visual styles. It also revealed that the learners were not very interested in group work.

In the same year, Moghadam, Razavi, and Jayervand (2013) aimed to find out the relationship between the Iranian ESL (English as a Second Language) learners' intelligence and perceptual learning styles in English language learning. The main results of this study showed that the most preferred learning style was kinesthetic learning style whereas the less preferred style was individual learning style. And linguistic intelligence was the most used intelligence among the learners; however, musical intelligence was the least used intelligence among the students who participated in the study.

Nosratinia, Mojri, and Sarabchian (2014), intended to find the degree of relationship between Iranian EFL learners' learning styles and their preferences in using specific language learning strategies. This study revealed a statistically significant relationship between EFL learners' affective strategy.

Ramezani, Dehgahi, and Hashemi (2015) explored the learning style preferences of 40 Iranian students at Marefat Iranian high school in Kuala Lumpur. The results of the study revealed that learning style preferences of Iranian students were different according to their gender. Female students preferred auditory learning as their major learning style, while male students preferred kinesthetic more. In the same line, four years back Fahim and Samadian (2011), aimed at finding a relationship between the sensory style preference of learners and their years of experience as EFL students at secondary school level in Iran. The implication of this study was that there was in fact a significant relationship between the sensory style preference of learners and that the experienced learners showed a flexibility towards the different learning styles whereas the non-experienced showed no flexibility.

Vaezi and Shahroosvand (2015) investigated the relationship between Iranian EFL learners' and teachers' sensory preferences (Visual, Auditory, and Kinesthetic (VAK)) and the learners' achievement in speaking. Results of this study exposed the matching Iranian EFL learners' and teachers' sensory preferences (VAK) had a significant effect on the learners' achievement in speaking.

Up to the present time, no research has attempted to reveal the relationship between the EFL learners' preferred learning style and speaking learning strategies across proficiency. Hence, the present study aims at responding to the following question:

Is there a correlation between the learning styles of the participants and their preferred speaking strategy across proficiency?

\section{Method}

The participants of the present study included (146) EFL learners studying at two EFL schools in Tehran, Iran. Their age ranged from 16 to 32 . The participants were selected based on their level of proficiency. (Elementary $=51$, Intermediate $=51$, and Advance $=44$ ). A questionnaire on Six Category Speaking Strategy was developed to measure EFL learners' Speaking strategy on five-option Likert point scale. The questionnaire 
contained 25 items catering for six types of Speaking Strategies: Part of Speech Manipulation, Memorization and Retrieval, Word Invention, Body Language, Time Management, and L1 Use or Avoidance. The reliability of the questionnaire proved to be 0.768 alpha. Another instrument used was O'Brien's (1990) Sensory style inventory, with a reliability of 0.707 for this group. The $146 \mathrm{EFL}$ learners received the two instruments in two sessions.

\section{Data Analysis and Results}

The data were analyzed using multivariate ANOVA (MANOVA) which had three main assumptions; normality of the data, homogeneity of variances, and homogeneity of covariance matrices which were all supported. The analysis revealed that (1) The proficiency levels had a weak to moderate effect on the learning styles of Iranian EFL learners $\left(F(12,254)=.071, p=.667\right.$, partial $\eta^{2}=.036$ representing a weak to moderate effect size); (2) The preference of language learning strategies had a weak to moderate effect on the learning styles of the Iranian EFL learners $\left(F(24,516)=1.03, p=.421\right.$, partial $\eta^{2}=.046$ representing a weak to moderate effect size); and (3) There was a moderate interaction between proficiency levels and preference of language learning strategies on the learning styles of the Iranian EFL learners $(F(48,786)=1.12, p=.262$, partial $\eta^{2}=.064$ representing a moderate effect size).

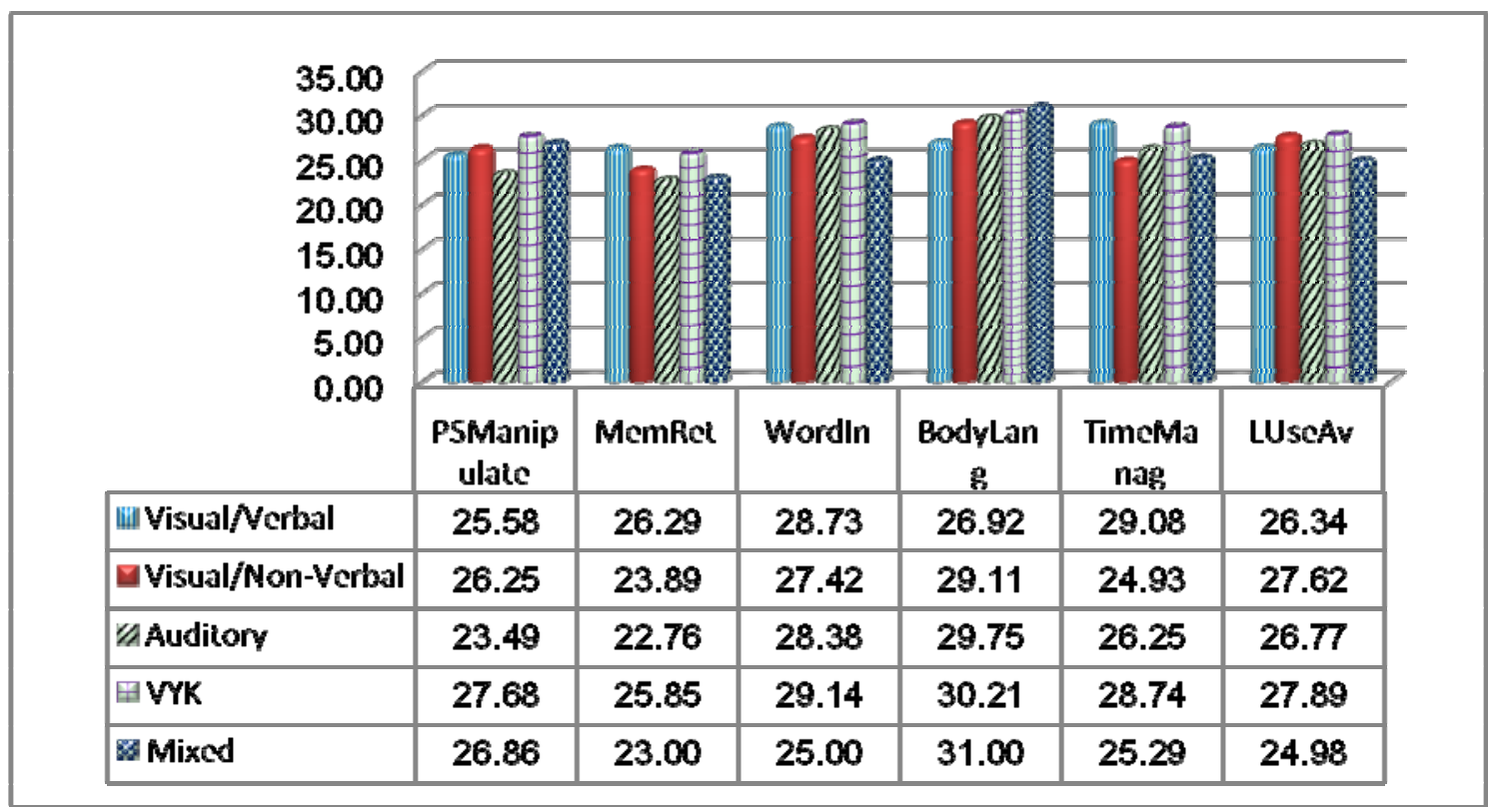

Figure 1. Learning styles by language learning strategy preferences.

\section{Discussion}

A number of studies have been conducted in Iran in recent years regarding EFL learning styles (Fahim \& Samadian , 2011; Ramezani, Dehgahi, \& Hashemi, 2015). Also two studies were conducted to probe the relationship between learning styles and strategy use (Nosratinia, Mojri, \& Sarabchian, 2014; Vaezi \& Shahroosvand, 2015).The first study revealed a statistically significant relationship between EFL learners' affective strategy and their learning style. The second study revealed that matching Iranian EFL learners' and teachers' sensory preferences (VAK) had a significant effect on the learners' achievement in speaking. Based on the results of the present study and to some extent in accordance to Nosratinia, Mojri, and Sarabchian (2014) 
findings, it was concluded that there was a moderate interaction between proficiency levels and preference of language learning strategies on the learning styles of the Iranian EFL learners.

\section{Conclusion}

There are various elements, including environmental factors, such as light, sound, design, etc., which may influence learning style preferences; in addition, emotional elements as well as social elements have equal contributions, too (Kinsella, 1995; Dunn \& Griggs, 2000). This research only explored sensory learning style preferences with regard to speaking strategies across proficiency, without considering the gender factor as most of the participants were male. Further research on other contributing factors will be useful to gain more insights into learning style preferences in individuals.

Numerous research studies have been conducted all around the world and in Iran too with reference to learning styles. O'Brien's (1990) sensory style was categorized into three distinctive groups, i.e., Visual, Auditory, and Haptic or Tactile. Up to now, it seems that English language course books have catered for the needs of language learners with regard to the visual and auditory sensory preference through the inclusion of a large number of pictures and CDs; however, the Haptic or Tactile learning style which is supported physically acting out what is being learnt, e.g., hands on work activities like are-work, are near to none except for young learners. This is of course culture bound and would seem not befitting at all to Eastern traditions.

In the end, it is hoped that this research will help the English teachers and English learners gain awareness of the fact that there is a weak to moderate interaction between proficiency levels and preference of language learning strategies on the learning styles EFL learners. Knowledge in this regard could perhaps assist teachers in lesson design, delivery methods, and appropriate material choice for effective classroom teaching.

\section{References}

Behabadi, F., \& Behfrouz, B. (2013). Learning styles and characteristics of good language learners in the Iranian context (A study on IELTS participants). International Journal on New Trends in Education and Their Implication, 4(2), 41-49.

Chamot, A. U. (2004). Issues in language learning strategy research and teaching. Electronic Journal of Foreign Language Teaching, 1(1), 14-26.

Dornyei, Z. (2005). The psychology of language teaching. Mulwah, NJ: Erlbaum.

Dunn, R., \& Griggs, S. A. (Eds.). (2000). Practical approaches to using learning styles in higher education. London: Westport, Connecticut.

Ellis, R. (1985). Understanding second language acquisition. Oxford: Oxford University Press.

Fahim, M., \& Samadian, T. (2011). Sensory style preference of EFL students in Iran. Theory and Practice in Language Studies, 1(6), 644-665.

Guilloteaux, M. J., \& Dornyei, Z. (2008). Motivating language learners: A classroom-oriented investigation of the effects of motivational strategies on student motivation. TESOL Quarterly, 42(1), 55-77.

Kinsella, K. (1995). Understanding and empowering diverse learners in ESL classroom. In J. Reid (Ed.), Learning styles in the ESL/EFL classroom. Boston, M. A.: Heinle and Heinle Publication.

Moghadam, S., Razavi, A., \& Jayervand, H. (2013).The Iranian ESL learners preferred conceptual learning style and the most used intelligence. Internation Journal of Psychology and Behavioural Research, 2(2), 86-90.

Nakatani, Y. (2006). Developing an oral communication strategy inventory. The Modern Language Journal, 90(2), 151-168.

Nosratinia, M., Mojri, Z., \& Sarabchian, E. (2014). Exploring the relationship between EFL learners' language learning styles and strategies. International Journal of Language Learning and Applied Linguistics World, 5(2), 253-264.

O’Brien, L. (1990). Learning channel preference checklist (LCPC). Rockville, MD: Specific diagnostic services.

Ortega, L. (2003). Syntactic complexity measures and their relationship to L2 proficiency: A research synthesis of college-level L2 writing. Applied Linguistics, 24(4), 492-518. 
Oxford, R. L. (1996). Employing a questionnaire to assess the use of language learning strategies. Applied Language Learning, 7 , $25-45$.

Ramezani, A. E., Dehgahi, M., \& Hashemi, H. (2015). An exploratory study of the language-learning style preferences of Iranian EFL high school students. Advances in Language and Literary Studies, 6(2), 151-159.

Razmjoo, S. A., \& Ghasemi, A. S. (2011). A model of speaking strategies for EFL learners. The Journal of Teaching Language Skills, 3(3), 115-142.

Reid, J. M. (1987). The learning style preferences of ESL students. TESOL Quarterly, 21(1), 87-111.

Reid, J. M. (1995). Learning styles in the ESL/ EFL classroom. Boston: Heinle and Heinle.

Rubin, J. (1987). Learner strategies: Theoretical assumptions, research history and typology. In A. Wenden and Joan Rubin (Eds.), Learner strategies and language learning (pp. 15-29). Eaglewood Cliffs, NJ: Prentice Hall.

Stern, H. H. (1992). Issues and options in language teaching. Oxford: Oxford University Press.

Vaezi, S., \& Shahroosvand, H. R. (2015). Iranian EFL learners' and teachers' sensory preferences and the learners' speaking ability. International Journal of English Language Education, 3(2), 14-27.

Vandergrift, L. (2005). Relationships among motivations, orientations, meta-cognitive awareness and proficiency in L2 listening. Applied Linguistics, 26(1), 70-89.

Williams, M., \& Burden, R. L. (1997). Psychology for Language Teachers. Cambridge: Cambridge University Press.

Wu,Y. L. (2008). Language learning strategies used by students at different proficiency level. Asian EFL Journal, 10(4), 75-95.

Yaman, S., \& Kavasoglu, M. (2013). The adaptation study of oral communication strategy inventory into Turkish. International Journal of Human Sciences, 10(2), 400-419.

Yang, M. N. (2007). Language learning strategies for junior college students in Taiwan: Investigating Ethnicity and proficiency. Asian EFL Journal, 9(2), 35-57. 